\title{
Habit History in Oral Submucous Fibrosis: Have We Over Emphasized?
}

\author{
Sheshaprasad R ${ }^{1 *}$, Anuradha Pai ${ }^{2}$, Anisha Yaji ${ }^{3}$
}

\begin{abstract}
Aim: Correlation of habit duration and frequency with clinical grading and histopathologic grouping of oral submucous fibrosis (OSMF). Materials and methods: 48 patients with OSMF were included in the study. Detailed history of each patient, clinical profile and habit history were recorded. Biopsy was performed for histopathological correlation. All the findings were correlated with Kerr et al and Khanna and Andrade classification. Statistical Analysis: Kruskal-wallis test was performed to assess the correlation between the study findings. Results: Out of 48 OSMF cases majority were males. Maximum cases were in clinically and histopathologically respectively. Mouth opening was directly proportional with histopathological grouping as per Khanna et al. No correlation between frequency and habit duration with respect to different stages or severity of the OSMF was noted. Conclusion: Disease staging of OSMF clinically and histopathologically is not directly impacted by habit duration and frequency. Rather than habit centered history and management accordingly, more focus should be given to genetics and susceptibility of patient for OSMF development and progression.
\end{abstract}

Keywords: Arecanut- correlation- Habit- OSMF

Asian Pac J Cancer Prev, 20 (2), 451-455

\section{Introduction}

OSMF is predominant among the people of South Asia and is closely associated with the habit of areca nut chewing. Evidence shows that areca nut greatly contributes towards exaggerating the occurrence of OSMF (Goel et al., 2010). The prevalence of OSMF in 2010 was reported to be $6.42 \%$ with an estimate of 5 million Indians suffering from this condition (Nigam et al., 2004). Oral fibrosis is caused due to increased synthesis of collagen, and in turn induces the production of free radicals and reactive oxygen species. This leads to high rate of oxidation/peroxidation of polyunsaturated fatty acids which affect essentials of cell membrane, which may induce tumorigenesis (Ajagaokar et al., 2016). Since a lot of emphasis is laid on the arecanut habit in contribution of OSMF, this study was under taken to assess the impact of habit frequency and duration with clinical staging and histopathological grading.

\section{Materials and Methods}

\section{Methodology}

The present study was carried out in the department of Oral Medicine and Radiology, the Oxford Dental College and Hospital, Bangalore. The ethical board clearance was obtained. 48 subjects diagnosed with OSMF who consented to participate were included in the study. Clinical details including name, age, gender and habits history along with duration of habit in years, frequency of habit per day, style of chewing i.e. spitting, swallowing and duration taken to chew was recorded on pre decided proforma. Mouth opening was measured using Vernier caliper. Clinical Grading of the lesion was performed using Kerr et al., (2011) classification (Table-1). After that a biopsy was taken from subjects for histopathologic grouping by Ranganathan and Mishra (2006) (Table-2).

\section{Statistical analysis}

The data obtained were tabulated and analysed using SPSS software version SPSS v.22 software IBM., Corp.

Comparison of mean duration and frequency of habit between different of OSMF clinically and histopathologically were done using Kruskal Wallis Test.

\section{Results}

This study included a total of 48 subjects with OSMF out of which $81.2 \%$ were males and $18.8 \%$ females. Majority of the subjects were in the age group of $20-30$ 
Table 1. Kerr e al., (2011) Classification

\begin{tabular}{|c|c|}
\hline Grade 1- Mild & $\begin{array}{l}\text { Any features of the disease triad for OSMF (burning, depapillation, blanching or leathery mucosa) may } \\
\text { be reported - and inter-incisal opening }>35 \mathrm{~mm}\end{array}$ \\
\hline Grade 2 - Moderate: & Above features of OSMF + inter-incisal limitation of opening $20-35 \mathrm{~mm}$ \\
\hline Grade 3 - Severe: & Above features of OSMF + inter-incisal opening $<20 \mathrm{~mm}$ \\
\hline Grade $4 \mathrm{~A}-$ & OSMF + other potentially malignant disorder on clinical examination \\
\hline Grade 4B - & OSMF with any grade of oral epithelial dysplasia on biopsy \\
\hline Grade 5 - & OSMF + oral squamous cell carcinoma (SCC) \\
\hline
\end{tabular}

Table 2. Khanna and Andrade., (1995) Classification

\begin{tabular}{lll}
\hline Group & \multicolumn{1}{c}{ Clinical } & \multicolumn{1}{c}{ Histology } \\
\hline $\begin{array}{l}\text { Group I: Very } \\
\text { early cases: }\end{array}$ & $\begin{array}{l}\text { Common symptom is burning sensation } \\
\text { in the mouth, acute ulceration and } \\
\text { recurrent stomatitis and not associated } \\
\text { with mouth opening limitation. }\end{array}$ & $\begin{array}{l}\text { Fine fibrillar collagen network interspersed with marked } \\
\text { edema, blood vessels dilated and congested, large aggregate } \\
\text { of plump young fibroblasts present with abundant cytoplasm, } \\
\text { inflammatory cells mainly consist of polymorphonuclear } \\
\text { leukocytes with few eosinophils. The epithelium is normal. }\end{array}$ \\
$\begin{array}{ll}\text { Group II: Early } \\
\text { cases }\end{array}$ & $\begin{array}{l}\text { Buccal mucosa appears mottled and } \\
\text { marble like, widespread sheets of }\end{array}$ & $\begin{array}{l}\text { Juxta-epithelial hyalinizalion present, collagen present as } \\
\text { thickened but separate bundles, blood vessels dilated and }\end{array}$ \\
& $\begin{array}{l}\text { fibrosis palpable, interincisal distance } \\
\text { of 26 to 35 mm. }\end{array}$ & $\begin{array}{l}\text { congested, young fibroblasts seen in moderate number, } \\
\text { inflammatory cells mainly consist of polymorphonuclear }\end{array}$ \\
& & $\begin{array}{l}\text { leukocytes with few eosinophils and occasional plasma cells, } \\
\text { flattening or shortening of epithelial rete-pegs evident with }\end{array}$ \\
varying degree of keratinization.
\end{tabular}

years $(64.6 \%)$ and $6.3 \%$ of them above 60 years. (Table 3 )

A comparison between mean habit duration and frequency with grading of mouth opening using Kerr et al classification was done. Maximum subjects $(n=40)$ were in grade 2 with a mouth opening of 20-35 mm. with a mean of 7.4 years of habit duration and a frequency ranging from 1 time to 20 times per day.(Table 4) Grade

Table 3. Distribution of Sociodemographic Characteristics among Study Patients

\begin{tabular}{llcc}
\hline Variable & & $\mathrm{n}$ & $\%$ \\
\hline Sex & Males & 39 & $81.20 \%$ \\
& Females & 9 & $18.80 \%$ \\
Age Group & $20-30 \mathrm{yrs}$ & 31 & $64.60 \%$ \\
& $31-40 \mathrm{yrs}$ & 11 & $22.90 \%$ \\
& $41-50 \mathrm{yrs}$ & 2 & $4.20 \%$ \\
& $51-60 \mathrm{yrs}$ & 1 & $2.10 \%$ \\
Age & $>60 \mathrm{yrs}$ & 3 & $6.30 \%$ \\
& Mean and SD & 32.4 & 12 \\
\hline
\end{tabular}

1 and 5 had only one subject with 50 years and 1 year of duration respectively. The correlation between the habit duration and frequency with disease severity was not significant. When the clinical symptom was correlated

Table 4. Comparison of Mean Duration (in yrs) and Frequency (Pkts/ day)of Gutkha Intake between Different Grades of OSMF as per Kerr et al Grading System Using Kruskal Wallis Test

\begin{tabular}{lccccccc}
\hline $\begin{array}{l}\text { Variables / } \\
\text { Grades }\end{array}$ & $\mathrm{N}$ & Mean & $\mathrm{SD}$ & Min & Max & $\mathrm{H}$ & P-Value \\
\hline $\begin{array}{c}\text { Duration } \\
\text { Grade 1 }\end{array}$ & 1 & 1 &.. & 1 & 1 & 6.205 & 0.1 \\
Grade 2 & 40 & 7.4 & 4.8 & 1 & 20 & & \\
Grade 3 & 6 & 5.7 & 4.1 & 3 & 14 & & \\
Grade 5 & 1 & 50 &.. & 50 & 50 & & \\
Frequency & & & & & & & \\
Grade 1 & 1 & 10 &.. & 10 & 10 & 2.886 & 0.41 \\
Grade 2 & 40 & 7.7 & 5.9 & 2 & 30 & & \\
Grade 3 & 6 & 6.2 & 3.1 & 3 & 10 & & \\
Grade 5 & 1 & 15 &.. & 15 & 15 & & \\
\hline
\end{tabular}



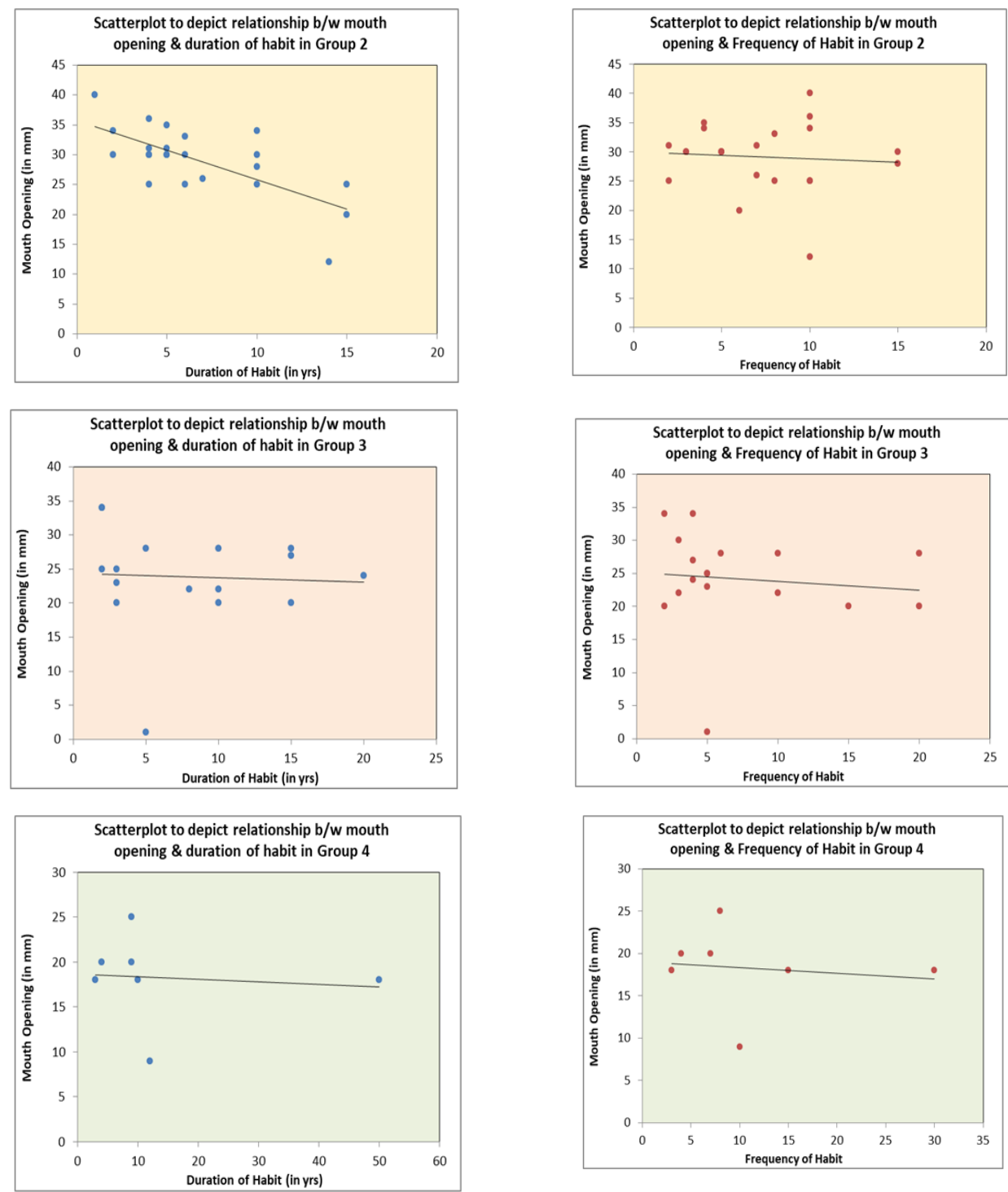

Figure 1. Scatterplot Depicting Relation between Frequency and Duration of Habit with Different Clinical Groups of OSMF

Table 5. Comparison of Mean Mouth Opening Measurement (in $\mathrm{mm}$ ) among the Study Patients between Different HP Grouping as per Khanna and Andrade et al Grouping System Using Kruskal Wallis Test

\begin{tabular}{|c|c|c|c|c|c|c|c|}
\hline $\begin{array}{l}\text { Variables / } \\
\text { Groups }\end{array}$ & $\mathrm{N}$ & Mean & SD & Min & $\operatorname{Max}$ & $\mathrm{H}$ & P-Value \\
\hline \multicolumn{8}{|c|}{ Mouth Opening } \\
\hline Group 1 & 1 & 32 & .. & 32 & 32 & 18.012 & $<0.001 *$ \\
\hline Group 2 & 23 & 29.1 & 5.8 & 12 & 40 & & \\
\hline Group 3 & 17 & 24.2 & 7.4 & 1 & 34 & & \\
\hline Group 4 & 7 & 18.3 & 4.8 & 9 & 25 & & \\
\hline
\end{tabular}

with histopathologic grading, Group 2 had maximum subjects $(\mathrm{N}=17)$ and group 1 minimum $(\mathrm{N}=1)$ according to Khanna and Andrade et al classification. (Table 5) Group 4 cases had least mouth opening of $18.2 \mathrm{~mm}$ as compared to group 2 which had a mouth opening of $29.1 \mathrm{~mm}$. As the mouth opening decreased the histopathological grouping increased. The correlation between mouth opening and histopathologic grading was statistically significant $(\mathrm{p}=<0.001)$.

Table 6. Different Classifications Used in Studies and Their Findings

\begin{tabular}{lcccc}
\hline Study & Participnts & Classification used & $\begin{array}{c}\text { Positive Habit and disease } \\
\text { severity corelation }\end{array}$ & $\begin{array}{c}\text { Positive clinical and histopathological } \\
\text { Correlation }\end{array}$ \\
\hline Goel et al & 100 & Kiran kumar et al & yes & No \\
Kumar et al & 75 & Kiran kumar et al & No & No \\
Debanath et al & 100 & Kiran kumar et al & Yes & No \\
Pandya S et all & 239 & Pindborg and Sirasat & Yes & - \\
Ali et al & 197 & Ranganathan et al & Yes & yes \\
Shivakumar et al & 50 & Kerr etal and Khanna etal &
\end{tabular}




\section{Discussion}

OSMF is a fibrotic disorder characterized by a presence of chronic low grade irritant i.e arecanut (Gandhi et al., 2017). Apart from this arecoline content in arecanut is also known to cause impaired endothelial function. Its effect on p53 inhibition, DNA repair suppression and DNA damage triggering in response to human endothelial cells have also been studied (Tseng et al., 2012). Many studies have emphasised on cessation of the areca nut chewing habit as the mainstay for the therapy (Prabhu et al., 2014; Bhatnagar et al., 2018). Angadi et al., (2011) suggested at a different mechanism of action of arecoline by increased differentiation of myofibroblasts in OSMF from various sources rather than a dose related pathogenesis. Also there was disagreement between studies regarding the relation between the development of OSMF and habit frequency and duration. Hence this study was under taken with the primary aim of assessing the impact of duration and frequency of habit with the clinical and histological expression of disease. The secondary aim of this article was addition of the demographic data with diverse use of areca nut to global OSMF data.

This study had a male predominance with majority (64.6\%) of them in the age group of 20 -30 years. Multiple classification systems have been used for clinical and histological grading of the OSMF (Ranganathan et al., 2006). In our study Kerr et al., (2011) classification was considered as this is one of the few classifications which include dysplasia. However no cases with dysplasia were seen in this study. Histopathologic classification of Khanna and Andrade was considered as Kerr et al classification did not consider histopathological changes other than dysplasia.

This study we observed that the clinical grades (mouth opening) had no statistically significant direct correlation with the habit duration or frequency. Ali et al., (2013) study on 197 subjects, Pandya et al., (2009) study which included 239 patients, Goel et al., (2011) study which included 100 patients and Shivkumar et al., (2010) study concluded that duration and frequency of areca nut use and had a direct effect on the incidence and severity of OSMF unlike our study (Table 6). Seedat et al., (2013) and Debanth et al., (2013) study similar to our study had noted that there was no positive correlation between habit duration and frequency and expression of disease. These studies concluded that chewing areca nut will lead to pathological changes in the mucosa, but, neither the frequency nor the duration of the habit, are accurate predictors of the extent of these changes or when they are likely to occur, which is clearly seen in our study. We also noted OSMF development $(n=7)$ 3-4 years after cessation of habit by patients. As we only included patients who were active habit users we did not include them in the study.

When the clinical grading was compared with histopathologic grouping there was significant correlation between the two. This was not in accordance with other studies with the exception of one study i.e Shivkumar et al., (2010) study (Goel et al.,2010; Debnath et al., 2013; Kumar et al., 2007). Goel et al., (2010) attributed this variation to the possibility of difference in the severity and extent of fibrosis in different regions of the oral mucosa and involved muscles.

However it's difficult to debate about the deeper tissue changes as our study used a histopathological grouping which limited its field of interest only to the subepithelial layers.

The difference in correlation between habit duration, frequency and disease progression may be largely attributed to genotoxic effects like polymorphisms of genes associated with collagen homeostasis brought about by exposure to habit (Shivkumar et al., 2010). This also explains why some patients though they have a shorter habit duration have severe OSMF as compared to their longer duration counter parts. Hence, when patients with arecanut habit have symptoms of OSMF, a long term follow up is warranted irrespective of its stage or grade. Habit cessation alone may not ensure prevention of disease incidence or progression.

\section{Limitations of our study}

1. We solely depended on patients reporting of habits for habit history.

2. We had not considered patients who had developed OSMF even after discontinuity of any tissue abusing products like arecanut, tobacco or alcohol for more than a year previously. Such patients also should be included as there have been incidences of lesion development as late as 10 years post discontinuation of habit.

3. There were severe differences in the number of patients in each group. A larger sample size would have probably eliminated this issue.

4. There is no fixed protocol for biopsy site selection in OSMF. This could have contributed to variation in histologic expression of disease.

In conclusion, this study shows that frequency and duration of habit showed no correlation with disease severity. Also in future more samples should be recruited from multiple centers with correlation of deeper tissue structure including muscular changes if any. Rather than habit centered history and management, more focus should be given to genetics and susceptibility of patient for OSMF development and progression. Also, when patients with initial stages of OSMF are encountered they must be emphasized and educated with the importance of long term follow up after habit cessation.

\section{References}

Ali FM, Aher V, Prasant MC, et al (2013). Oral submucous fibrosis: Comparing clinical grading with duration and frequency of habit among areca nut and its products chewers. $J$ Cancer Res Ther, 9, 471.

Angadi PV, Kale AD, Hallikerimath S (2011). Evaluation of myofibroblasts in oral submucous fibrosis: correlation with disease severity. J Oral Pathol Med, 40, 208-13.

Ajgaonkar AS, Belgaumi UI, Malik NA, et al (2016). Age and habit as determinants in oral submucous fibrosis (OSMF). Int J Cur Res, 8, 38831-4.

Bhatnagar S (2018). Clinical evaluation of different treatment methods for OSMF: A five-year experience with 144 cases. Oral Pathol and Oral Radiol, 4, 25-8. 
Debnath S, Mitra B, Paul B, et al (2013). A morphometric analysis of oral submucous fibrosis and its correlation with histological staging and clinical severity of trismus. Egyptian $J$ Ear Nose Throat Allied Sci, 14, 85-90.

Gandhi P, Prasad UC (2017). Evaluation of myofibroblasts in oral submucous fibrosis and oral squamous cell carcinoma: The pathogenesis and correlation. Dent Res J (Isfahan), 14, 314-20.

Goel S, Ahmed J, Singh MP, Nahar P (2010) Oral submucous fibrosis: A clinico-histopathological comparative study in population of southern Rajasthan. J Carcinogene Mutagene, 1, 108.

Kerr AR, Warnakulasuriya S, Mighell AJ, et al (2011). A systematic review of medical interventions for osmf and future research oppurtunities. Oral dis, 17, 42-57.

Kumar KK, Saraswathi TR, Ranganathan K, et al (2007). Oral submucous fibrosis- A clinicohistopathological study in Chennai. Indian J Dent Res, 18, 106-11.

Nigam NK, Aravinda K, Dhillon M, et al (2014). Prevalence of oral submucous fibrosis among habitual gutkha and areca nut chewers in Moradabad district. J Oral boil and Cranio Res, 4, 8e13.

Pandya S, Chaudhary AK, Singh M, et al (2009). Correlation of histopathological diagnosis with habits and clinical findings in oral submucous fibrosis. Head Neck Oncol, 1, 10.

Prabhu RV, Prabhu V, Chatra L (2014). Areca nut and its role in oral submucous fibrosis. J Clin Exp Dent, 6, e569-75.

Ranganathan K, Mishra G (2006). An overview of classification schemes for oral submucous fibrosis. J Oral Maxillofac Pathol, 10, 55-8.

Shivakumar GC, Sahana S (2010). Correlation between the functional and histological grading in OSMF. JIAOMR, 22, 133-5.

Tseng SK, Chang MC, Su CY (2012). Arecoline induced cell cycle arrest, apoptosis, and cytotoxicity to human endothelial cells. Clin Oral Invest, 16, 1267-73.

\section{(ब) $(1)(9$}

This work is licensed under a Creative Commons AttributionNon Commercial 4.0 International License. 